\title{
Forecast of Large Earthquake Emergency Supplies Demand Based on PSO-BP Neural Network
}

\author{
Dan CHANG, Yan WANG*, Rui FAN
}

\begin{abstract}
Since ancient times, earthquakes have been frequent in China. They have caused serious damage to people's lives and the economic conditions of the country. A large earthquake will cause serious casualties, and a large number of emergency supplies will be needed in the disaster area. However, since earthquakes regularly occur quickly, it is impossible to determine the demand for emergency supplies. Therefore, emergency supplies lose accuracy in distribution. In this paper, we adopt an indirect prediction method. We use particle swarm optimization to improve and optimize the initial weights and thresholds of the BP neural network. Then we predict the mortality rate and injury rate of a large earthquake. Hence the number of casualties and survivors can be obtained. Finally, quantitative relationships between the number of survivors, injured and different supplies are used to estimate the demand for various supplies. By comparing the BP neural network before the improvement, we find that the improved model has higher prediction accuracy and less prediction error. In addition the simulation value fits better with the desired output value. This paper enriches the modeling method for the study of demand prediction of large earthquake emergency supplies.
\end{abstract}

Keywords: BP neural network; demand forecasting; emergency supplies; large earthquake; particle swarm optimization (PSO)

\section{INTRODUCTION}

Since the 19th century, with the continuous development of science and technology, life quality has been improving. But the environment the people depend on for survival has been deteriorating, and the scale of natural disasters and the damage they cause are becoming more and more significant [1]. Due to the special geographical location of China, China has suffered from serious earthquake disasters for a long time. In the last 50 years, China experienced more than 5000 earthquakes, which not only cause a great loss to the national economy, but also pose serious risks to people's lives. In the 2008 Wenchuan earthquake, 100,000 square kilometers were directly and severely affected, with 68,977 people killed, 367,854 injured and 17,974 missing in just half a month. In 2017, the Jiuzhaigou earthquake caused 25 dead, 525 injured, 6 people lost, affected up to 176,492 people, and 73,671 houses damaged to varying degrees. It shows that people's production and life are being increasingly affected by earthquakes. To face continuous earthquakes, it has become increasingly important to know how to cope with earthquakes, although there are many difficulties and challenges [2].

Weak earthquakes do not cause much impact and do not result in substantial damage, and there is no great need for supplies. Accordingly, this paper gathers earthquakes of magnitude six or above, and this paper calls them large earthquakes. In order to minimize the impact of a large earthquake, besides active rescue, it is necessary to create conditions that allow people in the disaster area to survive and meet their needs for supplies in the first place. The first step is to have a timely and accurate estimate of the damage caused by the earthquake, which is extremely significant for the government to carry out follow-up work. Once a large earthquake occurs, the government will set up an emergency relief command center to guide the relief effort immediately. However, current decisions on emergency supplies are mainly made by expert experience, which is highly subjective, cannot meet the objective requirements of the actual early warning. If the demand for emergency supplies is not set appropriately, the subsequent rescue work is bound to be affected. If supply is delivered excessively, it will not only reduce the efficiency of supply transportation, but also waste human and supply resources. If supply is under-delivery, the demand for supply in the disaster area will not be met in time, and the situation of oversupply will be formed. It is possible to make people in the disaster area suffer from further injury and it is very unfavorable to the subsequent rescue. Thus, this paper studies the demand forecasting of large earthquake emergency supplies, which is of great significance. It plays an important role in reality.

In general, scholars have two ideas in predicting the demand for emergency supplies after an earthquake: direct prediction and indirect prediction. Direct prediction refers to using the algorithm to construct the prediction model of the demand for emergency supplies directly. It generally involves finding historical cases that are similar to the target case, using methods such as case inference to process fuzzy data, and calculating the demand for emergency supplies in the target case based on previous earthquake cases. Indirect prediction needs to consider the relationship between the casualty situation and the emergency supplies when predicting the demand for emergency supplies in the earthquake. In the indirect prediction, firstly, scholars will use the algorithm to construct the prediction model of the earthquake casualty situation. Then the relationship between casualties and different emergency supplies is used to estimate the demand for emergency supplies.

As scholars continue to research the demand for emergency supplies, the indirect prediction method gradually replaces the direct prediction. Scholars use the indirect prediction method to predict the casualties in earthquakes, and estimate the demand for emergency supplies based on the quantitative relationship between the casualty population and the demand for supplies. The quantitative relationship between casualty population and emergency supplies demand was first proposed by NieGaozhong et al [3], and the calculation formula is supply-demand $=$ demand person-days $*$ coefficient of supply-demand * climate coefficient * area coefficient. By analyzing data from five major earthquakes, he predicted 
the demand for particular emergency supplies in the 10 days after the earthquake, and also provided a table of demand coefficients for more than 80 emergency supplies, which provided the foundation for later studies. Chen Xi et al [4] proposed a gray model that used local population, house collapse rate, GDP, and earthquake intensity level to predict the mortality rate of an earthquake, after which the survival rate was calculated. Guo Jinfen [5] used a traditional BP neural network to predict the number of casualties of the earthquake. He Shanshan et al [6] were the first to use support vector machine prediction after genetic algorithm improvement to get the number of casualties after the earthquake. Then they introduced the knowledge of inventory management to estimate the demand for emergency supplies. Finally, they verified the higher prediction accuracy of his proposed model with data. Sun Chao [7] was first who classified the emergency supplies after the earthquake disaster into category A and category $\mathrm{B}$, and combined indirect and direct prediction. He used an improved BP neural network to predict the number of casualties at the beginning of the earthquake and then estimated the demand for Class A supplies. Cheng Qiongqiong [8] introduced a genetic algorithm to improve the prediction of casualty rates in earthquakes using BP neural networks and then estimated the demand for different emergency supplies. Zhou Min [9] used a combination of gray theory and Markov chain model in predicting the number of casualties, which improved the accuracy of the prediction and then estimated the demand for emergency supplies.

On the choice of algorithm, BP neural networks are used to address problems in various fields and have been widely used in combination with other disciplines. Aminian F et al [10] introduced a coefficient to measure the predictive power of neural networks for economic indicators. They found that the predictive results of neural networks were better than linear regression models. Mamat T et al [11] developed a BPNN-MIV model to quantify the impact of various factors on the level of development of agricultural mechanization. It was based on backpropagation neural network and mean impact value methods. In order to guarantee the precision of the parameters of the probability integral method, Chi, S.et al [12] started from optimizing input and improving algorithm with an algorithm integrating the genetic algorithm and particle swarm optimization. Lazar, M.et al [13] used BP algorithm to narrow the search span with the LM algorithm to find the best ANN for reflectance reconstruction.

BP neural networks are one of the most frequent methods to be used in building prediction models. However, since the algorithm itself tends to fall into a local optimum, many scholars combine BP neural networks with other algorithms to compensate for this shortcoming in order to achieve better prediction results. The PSO algorithm is efficient, easy to implement, requires fewer parameters. In addition, it can find the global optimal solution quickly. Thus, it can complement the shortcomings of the BP neural network. This paper will combine the two methods to predict the demand for large earthquake emergency supplies.

\section{LARGE EARTHQUAKE EMERGENCY SUPPLIES DEMAND ANALYSIS AND CALCULATION \\ 2.1 Large Earthquake Emergency Supplies Demand Analysis}

The classification of emergency supplies for a large earthquake should meet three principles, namely, purpose, distinguishability, and uniqueness. Purpose means that when classifying supplies, it is clear that the purpose of doing so is to improve the efficiency of emergency response. It is also to facilitate the subsequent dispatch of supplies. Distinguishability means that each supply should be easy to distinguish and ensure a clear classification of supplies. Uniqueness is the fact that a supply can only appear in one category and there can be no crossover.

In this paper, based on the previous research on the classification of supplies and the special characteristics of emergency supplies in large earthquakes, emergency supplies are divided into the following four categories [14]: life-saving equipment, medical supplies, food supplies, cold items supplies. Compared with ordinary supplies, emergency supplies have the following characteristics: suddenness, uncertainty, supply-side dominance, timeliness, stage, and the weak economy.

For the prediction of the demand for emergency supplies, this paper is to predict the demand for supplies in the first instance after the occurrence of a large earthquake. The casualties and the extent of the damage in the disaster area are not clear, so it is necessary to build a prediction model to make the prediction. The focus of this paper is on how many emergency supplies should be supplied to the disaster area in the initial period after a major earthquake, and to build a suitable model to predict the demand for emergency supplies. At this stage, the government supplies food to the disaster area mainly to solve the problem of feeding the affected people. And the most efficient and effective food to sustain life in this environment is convenience food. So the food supplied by the government to the disaster area mainly includes bottled drinking water, bread, compressed cookies, and other convenience food [15]. In addition, large earthquake is often accompanied by the collapse of buildings. Therefore, the main injuries suffered by the injured are crush injuries. So the basic medicines include anti-inflammatory drugs, disinfectants and plasma products, and so on. Also for the safety and security of people's lives in disaster areas, emergency supplies such as quilts and tents of the cold-proof category are essential.

In summary, this paper estimates the demand for three types of emergency supplies, namely, food, medical supplies, and cold items, in the disaster area at the beginning of a large earthquake.

\subsection{Large Earthquake Emergency Supplies Demand Calculation}

In the initial period after a large earthquake, the beginning moment of rescue work to the disaster area is noted as 0 , and the subsequent timing is in hours and noted as $t(t=0,1,2, \ldots)$. Let $\delta_{i}(t)$ denote the total population of the disaster area and $X_{i}(t)$ be the cumulative number of dead in the disaster area at time $t$. By using the following equation, we are able to calculate the number of survivors 
$S_{i}(t)$, in the disaster area $i$ at time $t$.

$$
S_{i}(t)=\delta_{i}(t)-X_{i}(t)
$$

Food is a continuously consumable supply that is used to meet the needs of the survivors in the disaster area, and therefore the needs to be supplied regardless of the cycle. Warm goods are used for a long period of time, and after meeting the needs of the survivors in the disaster area initially, they do not need to be supplied in the next period of time. Medical supplies are also continuously consumable supplies, and the injured are the target audience.

Eq. (2) can estimate the demand $D_{i}^{k}(t)$ for emergency supplies $k$ in a certain period of time in the disaster area $i$, where $k_{1}$ denotes food and drink, $k_{2}$ denotes warming items, and $k_{3}$ denotes medical supplies.

$D_{i}(t)=\left\{\begin{array}{l}a^{k_{1}} \cdot S_{i}(t) \cdot L T+Z_{\partial} \cdot \sigma_{i}^{k_{1}}(t) \cdot(L T)^{-1 / 2} \\ a^{k_{2}} \cdot S_{i}(t)-B_{i}^{k_{2}}-\sum_{\varepsilon=1}^{i=1} A_{i}^{k_{2}}(t-\varepsilon) \\ a^{k_{3}} \cdot P_{i}(t) \cdot L T+Z_{\partial} \cdot \sigma_{i}^{k_{3}}(t) \cdot(L T)^{-1 / 2}\end{array}\right.$

$\sigma_{i}^{k}(t)=\left(\sum_{i=0}^{t-1}\left[D^{k}(t-i)-\bar{D}(t)\right]^{2} / t\right)^{-1 / 2}$

$\bar{D}_{i}^{k}(t)=\left[\sum_{i=0}^{t-1} D^{k}(t-i)\right] / t$

In Eq. (2), $\sigma_{i}^{k}(t)$ represents the standard deviation of the hourly average demand for emergency supplies $k$ in the disaster area $i$ as of moment $t$, which can be obtained from Eq. (3). $B_{i}^{k}$ is the quantity of emergency supplies $k$ stored in the disaster area $i$ before the earthquake. $A_{i}^{k}=(t-\varepsilon)$ is the number of emergency supplies $k$ received in the disaster area $i$ during time $t-\varepsilon$. In Eq. (4), $\bar{D}_{i}^{k}(t)$ is the average hourly demand for emergency supplies $k$ in disaster area $i$ before moment $t$.

\section{CONSTRUCTION OF A LARGE EARTHQUAKE EMERGENCY SUPPLIES DEMAND FORECASTING MODEL BASED ON PSO-BP NEURAL NETWORK}

It is difficult to predict the exact number of casualties in a large earthquake because of various factors that cause casualties in the disaster area. These factors are nonlinear, random, discrete, and uncertain. In this paper, we use an indirect prediction method to predict the casualty rate of a large earthquake and then estimate the demand for various emergency supplies in the disaster area according to the formula. The specific prediction process is shown in Fig. 1 .

\subsection{Sample Set Processing}

Based on the availability of data, a total of eight variables were selected in this paper as indicators of the casualty rate of large earthquake: earthquake time, magnitude, intensity of earthquake damage, seismic intensity of buildings, housing collapse, affected population, population density, and earthquake forecast level.

By consulting some official websites and materials, such as China Earthquake Information Network, Earthquake Data Sharing Center, the division of national administrative regions, statistical yearbooks of various places, the division table of seismic intensity in various places, and the Case of China, a total of 20 sets of data were collected in this paper as a sample set for the study. They are all of the earthquakes of magnitude six or above that occurred in China. Example of data interpretation: Case 1 was a 6.0 magnitude earthquake that occurred at 22:55 on June 17, 2019, and the earthquake occurred at a time, not between 0 and 6 , so it was recorded as 1 . The intensity of the epicenter reached level VI, and a total of 30,655 houses had different degrees of damage or collapse. The number of people affected reached 243,880 due to the high population density of the affected area, which reached 340 people $/ \mathrm{km}^{2}$. The seismic intensity of the disaster area was 6. There was no timely forecast before the earthquake, so the forecast level was 1 . Tab. 1 shows the relevant data of these earthquakes.

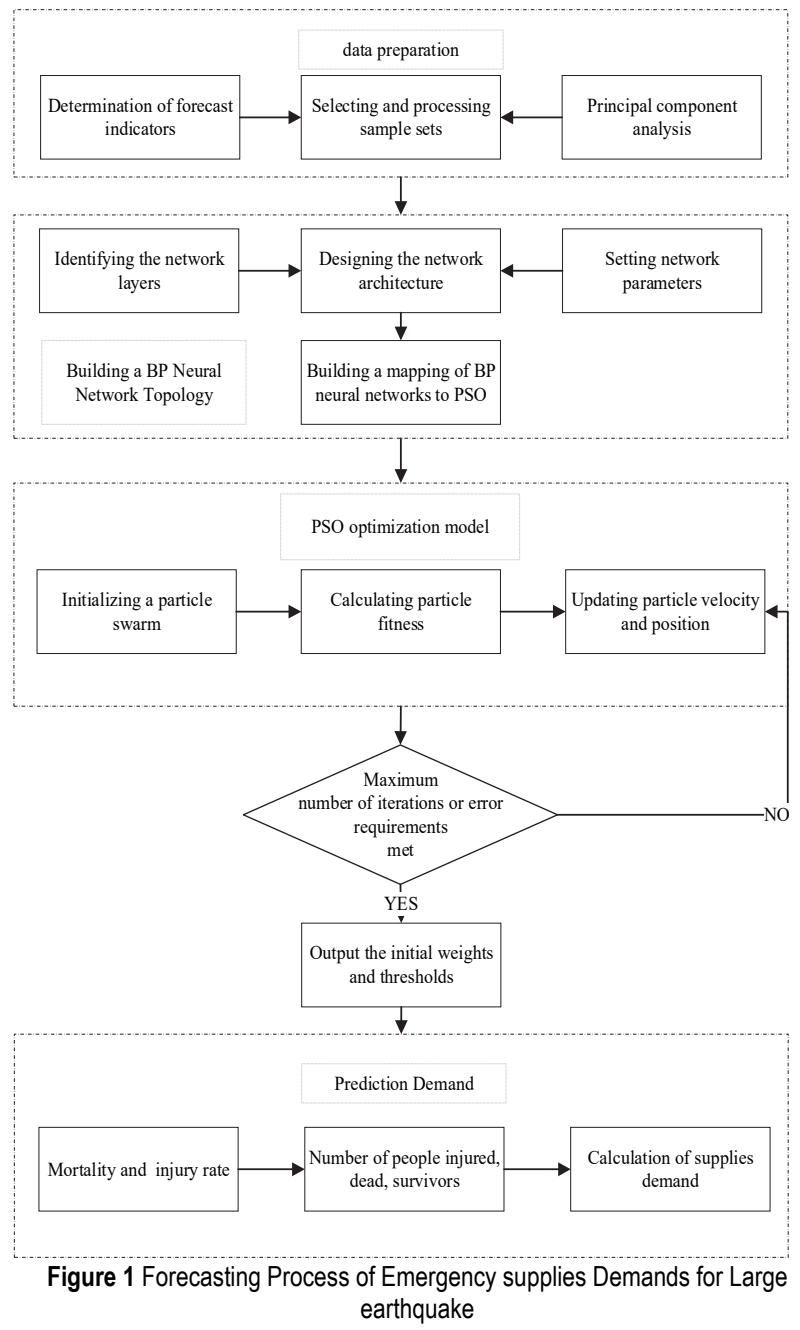


Table 1 Data of the Earthquakes

\begin{tabular}{|c|c|c|c|c|c|c|c|c|}
\hline No. & Time & Earthquake Level & Damage Intensity & Fence Intensity & Housing Collapse & $\begin{array}{c}\text { Affected } \\
\text { Population }\end{array}$ & $\begin{array}{c}\text { Population } \\
\text { Density }\end{array}$ & $\begin{array}{c}\text { Forecast } \\
\text { Level }\end{array}$ \\
\hline 1 & 1 & 6.0 & VI & 6 & 30655 & 243880 & 340 & 1 \\
\hline 2 & 1 & 6.9 & VIII & 7 & 3000 & 12000 & 2 & 1 \\
\hline 3 & 1 & 6.6 & VIII & 7 & 5469 & 10500 & 12 & 1 \\
\hline 4 & 1 & 7.0 & IX & 8 & 73671 & 176492 & 3000 & 1 \\
\hline 5 & 1 & 6.7 & IX & 7 & 571 & 2546 & 7 & 1 \\
\hline 6 & 1 & 7.3 & IX & 7 & 13662 & 455573 & 4 & 1 \\
\hline 7 & 1 & 6.5 & IX & 7 & 900 & 1088400 & 265 & 1 \\
\hline 8 & 1 & 7.0 & IX & 7 & 910 & 1520000 & 122 & 2 \\
\hline 9 & 1 & 7.1 & IX & 7 & 3800 & 200000 & 7 & 1 \\
\hline 10 & 1 & 6.6 & VIII & 7 & 200000 & 870000 & 320 & 1 \\
\hline 11 & 1 & 6.1 & VIII & 7 & 7455 & 130311 & 121 & 3 \\
\hline 12 & 1 & 6.1 & VIII & 7 & 36500 & 103054 & 101 & 3 \\
\hline 13 & 2 & 6.4 & IX & 9 & 360000 & 186000 & 73 & 2 \\
\hline 14 & 1 & 6.5 & VII & 7 & 31932 & 995000 & 19 & 1 \\
\hline 15 & 1 & 7.0 & VIII & 7 & 959000 & 1075000 & 11 & 2 \\
\hline 16 & 1 & 6.6 & IX & 7 & 86 & 120000 & 50 & 1 \\
\hline 17 & 1 & 7.6 & IX & 7 & 1858800 & 2500000 & 49 & 3 \\
\hline 18 & 1 & 6.8 & IX & 7 & 40500 & 536000 & 104 & 2 \\
\hline 19 & 1 & 7.9 & $\mathrm{X}$ & 7 & 18567 & 1500000 & 6 & 3 \\
\hline 20 & 2 & 7.9 & XI & 5 & 656136 & 2300000 & 11000 & 1 \\
\hline
\end{tabular}

Note:

1. Earthquakes occurring between 0:00 a.m. and 6:00 a.m. are marked as 2, while the rest of the day is marked as 1.

2. Seismic forecast level: Level 1 means no forecast at all; Level 2 means a forecast with deviations; Level 3 means a very accurate forecast.

Principal component analysis was performed on the eight indicators in the above section. The results of the eigenvalues, contribution rates and cumulative contribution rates of each principal component are shown in Tab. 2.

Table 2 Characteristic Value, Contribution Rate and Cumulative Contribution Rate of Principal Components

\begin{tabular}{|c|c|c|c|}
\hline Principal components & Eigenvalues & Contribution rate / \% & Cumulative contribution rate / \% \\
\hline Time & 3.3973 & 42.4658 & 42.4658 \\
\hline Earthquake Level & 1.6093 & 20.1166 & 62.5824 \\
\hline Damage Intensity & 1.1577 & 14.4716 & 77.0540 \\
\hline Fence Intensity & 0.8302 & 10.3780 & 87.4320 \\
\hline Housing Collapse & 0.5729 & 7.1609 & 94.5929 \\
\hline AffectedPopulation & 0.2001 & 2.5018 & 97.0947 \\
\hline Population Density & 0.1248 & 1.5596 & 98.6543 \\
\hline Forecast Level & 0.1077 & 1.3457 & 100 \\
\hline
\end{tabular}

Table 3 Coefficients of the First 6 Principal Components

\begin{tabular}{|c|c|c|c|c|c|}
\hline Time & Earthquake Level & Damage Intensity & Fence Intensity & Housing Collapse & Affected Population \\
\hline 0.3022 & -0.2402 & 0.5410 & -0.5132 & 0.0234 & 0.2181 \\
\hline 0.4460 & 0.0885 & -0.0217 & 0.5257 & -0.1963 & -0.0934 \\
\hline 0.4086 & -0.0451 & 0.3823 & 0.4794 & 0.1781 & -0.1506 \\
\hline-0.2415 & 0.3061 & 0.6828 & 0.0940 & -0.3641 & 0.1339 \\
\hline 0.3200 & 0.4422 & -0.1222 & -0.3871 & -0.4976 & -0.4920 \\
\hline 0.4502 & 0.2477 & -0.2615 & -0.0559 & -0.0962 & 0.7629 \\
\hline 0.4170 & -0.4184 & 0.0156 & -0.2246 & 0.1671 & -0.2605 \\
\hline 0.0736 & 0.6377 & 0.1034 & -0.1348 & 0.7155 & -0.1059 \\
\hline
\end{tabular}

As shown in the above table, the cumulative contribution of the first six principal components has reached $97.0947 \%$, which exceeds $95 \%$. So, the first six principal components are finally selected as the input variables of the BP neural network in this paper. The coefficients of the first 6 principal components are listed in Tab. 3. Each of the 8 original variables is represented by $x_{1}$, $x_{2}, \ldots, x_{8}$. The expressions for the first 6 principal components $y_{1}, y_{2}, \ldots, y_{6}$ can be obtained using the data and formulas in the table above as follows.

After the principal component analysis, the input variables of the BP neural network, which are the first six principal component scores $\mathrm{p} 1$ of the collected samples, are shown in Tab. 4.

$$
\begin{aligned}
& y_{1}=0.3022 x_{1}+0.4460 x_{2}+0.4086 x_{3}-0.2415 x_{4}+ \\
& +0.3200 x_{5}+0.4502 x_{6}+0.4170 x_{7}+0.0736 x_{8} \\
& y_{2}=-0.2402 x_{1}+0.0885 x_{2}-0.0451 x_{3}+0.3016 x_{4}+ \\
& +0.4422 x_{5}+0.2477 x_{6}-0.4184 x_{7}+0.6377 x_{8} \\
& y_{3}=0.5410 x_{1}-0.0217 x_{2}+0.3823 x_{3}+0.6828 x_{4}- \\
& -0.1222 x_{5}-0.2615 x_{6}+0.0156 x_{7}+0.1034 x_{8} \\
& y_{4}=-0.5132 x_{1}+0.5257 x_{2}+0.4794 x_{3}+0.0940 x_{4}- \\
& -0.3871 x_{5}-0.0559 x_{6}-0.2246 x_{7}-0.1348 x_{8} \\
& y_{5}=0.0234 x_{1}-0.1963 x_{2}+0.1781 x_{3}-0.3641 x_{4}- \\
& -0.4976 x_{5}-0.0962 x_{6}+0.1671 x_{7}+0.7155 x_{8} \\
& y_{6}=0.2181 x_{1}-0.0934 x_{2}-0.1506 x_{3}+0.1339 x_{4}- \\
& -0.4920 x_{5}+0.7629 x_{6}-0.2605 x_{7}-0.1059 x_{8}
\end{aligned}
$$


Table 4 Scores of the 6 principal components in samples

\begin{tabular}{|c|c|c|c|c|c|c|}
\hline No. & Time & Earthquake Level & Damage Intensity & Fence Intensity & Housing Collapse & Affected Population \\
\hline 1 & -1.9880 & -1.0848 & -1.8980 & -1.6312 & 0.0559 & 0.1243 \\
\hline 2 & -1.0130 & -0.6474 & -0.1864 & 0.3567 & -0.3944 & -0.3009 \\
\hline 3 & -1.2570 & -0.6961 & -0.1715 & 0.0634 & -0.2878 & -0.2544 \\
\hline 4 & -0.2258 & -0.6342 & 1.0587 & 0.7001 & -0.6582 & -0.5013 \\
\hline 5 & -0.7932 & -0.7293 & 0.1928 & 0.6236 & -0.1477 & -0.4178 \\
\hline 6 & -0.0244 & -0.4714 & 0.0041 & 1.1606 & -0.4361 & -0.0815 \\
\hline 7 & -0.2731 & -0.4523 & -0.1679 & 0.3269 & -0.1955 & 0.6753 \\
\hline 8 & 0.4581 & 0.5703 & -0.2158 & 0.6281 & 0.4314 & 0.9069 \\
\hline 9 & -0.3458 & -0.5969 & 0.1043 & 0.9937 & -0.3207 & -0.2925 \\
\hline 10 & -0.5634 & -0.2825 & -0.5157 & -0.1902 & -0.5850 & 0.3659 \\
\hline 11 & -1.3980 & 0.7989 & 0.0644 & -0.7649 & 1.6264 & -0.3201 \\
\hline 12 & -1.3973 & 0.8212 & 0.0659 & -0.7899 & 1.5972 & -0.3762 \\
\hline 13 & -0.2656 & 0.4546 & 3.8163 & -1.5597 & -0.5010 & 0.3764 \\
\hline 14 & -1.1290 & -0.3255 & -0.8763 & -0.5865 & -0.5741 & 0.8624 \\
\hline 15 & 0.4497 & 1.4044 & -0.6826 & -0.5901 & -0.7218 & -0.4026 \\
\hline 16 & -0.7991 & -0.7152 & 0.1580 & 0.5147 & -0.1230 & -0.2871 \\
\hline 17 & 2.8934 & 3.5534 & -0.9475 & -0.5766 & -1.0428 & -0.3155 \\
\hline 18 & -0.2564 & 0.2677 & 0.1186 & 0.4674 & 0.5743 & -0.0927 \\
\hline 19 & 1.6585 & 1.4808 & 0.2320 & 1.7906 & 1.1237 & 0.4526 \\
\hline 20 & 6.2695 & -2.7156 & -0.1532 & -0.9320 & 0.5795 & -0.1211 \\
\hline
\end{tabular}

\subsection{BP Neural Network Construction}

A large amount of literature proves that three-layer BP neural networks are best trained with S-type functions for the implicit layer transfer function and linear functions for the output layer transfer function. Therefore, this paper uses a three-layer BP neural network, which includes an input layer, an implicit layer, and an output layer. The transfer function between the input layer and the implicit layer is an S-type function, and the transfer function between the implicit layer and the output layer is a linear function.

(1) Determining the number of network layers and nodes in the input and output layers:

The final prediction index determined in this paper is 6 , which means the input variables of the BP neural network are 6 . So, the number of nodes in the input layer is 6 . The prediction in this paper focuses on the mortality rate and injury rate of large earthquake when predicting the demand for emergency supplies, which means the output results of the BP neural network are the mortality rate and injury rate. So, the number of nodes in the output layer is 2.

(2) Determining the number of nodes in the hidden layer:

In this paper, the number of nodes in the implicit layer is varied from 8 to 14 according to the actual problem under study. Then the network is trained one by one, and the optimal number of nodes in the implicit layer is obtained through comparative analysis. The number of nodes in the hidden layer is 9 , and the network error is 0.0016099 , so the number of nodes in the hidden layer is 9 .

In this paper, the following parameters are considered when setting the network parameters.

(1) Transfer function:

In the research problem of predicting the demand for large earthquake emergency supplies, the specific transfer function between the input layer and the implied layer is the Tan-sigmoid function in the S-type function. And the specific transfer function between the implied layer and the output layer is the Purelin-type transfer function in the linear function.

(2) Learning rate:

In general, the learning rate is limited to $(0.1,0.8)$, which affects the change of the weights during the network training. In this paper, after several training sessions, the final learning rate is 0.3 .

(3) Training function:

The amount of data in this paper is relatively small, and the training function chosen after several comparisons and analyses is the train gdx function.

(4) Expected error:

After several times network training, we compare the error under the different number of nodes of the hidden layer and finally determine the expected error of this paper is 0.001 .

\subsection{PSO Optimization Model Construction}

In this paper, the output of the PSO algorithm is used as the initial weights and thresholds of the BP neural network, and then the network is trained. In other words, on the basis of determining the structure of the neural network, the mapping between the two methods is established. Then the error of the output of the BP neural network is used as the fitness function of the PSO algorithm. The optimal solution of the PSO algorithm is finally used as the initial weights and thresholds of the BP neural network in this cyclic iteration.

In this paper, the dimensional component of each particle in the PSO algorithm corresponds to a weight in the BP neural network. This optimization idea mainly uses the PSO algorithm to optimize the weights and thresholds in the error backpropagation of the BP neural network. In this paper, Mean Square Error (MSE), to be used as the fitness function of the PSO algorithm, is adopted in the following form.

$$
M S E=\sum_{i=1}^{N} \sum_{j=1}^{M}\left(y_{j i}^{d}-y_{j i}\right)^{2} / N
$$

where $N$ denotes the number of samples trained. $y_{j i}^{d}$ denotes the expected output value of the $j$ network output node for the $i$ sample. $y_{i j}$ denotes the actual output value of the $i$ sample at the $j$ network output node. $m$ denotes the number of nodes in the output layer of the BP neural network. 
Combined with the parameter analysis of the PSO algorithm, the number of particles $N=40$ is finally selected. The dimensionality $D$ of the solution space is: $D=(n+m) \cdot h+h+m$, i.e. $D=110$, where $n$ is the number of neuron input nodes, $m$ is the number of output nodes, $h$ is the number of nodes in the hidden layer. The maximum number of iterations $T_{\max }=1000$. The learning factors $c_{1}$ and $c_{2}$ are 2.0. According to the proposed linear decreasing weight strategy, the inertia weights 1 in this paper are calculated as follows.

$$
w=w_{\max }-\left(w_{\max }-w_{\min }\right) \cdot t / T_{\max }
$$

where $w_{\max }=0.9, w_{\min }=0.4, t$ is the current number of iterations and the maximum limit speed $V_{\max }=1$.

The specific optimization steps are as follows.

Step 1: Initialization of PSO algorithm and BP neural network. The topology of the BP neural network is established according to the network structure and parameters designed above. The dimension of the whole search space in the particle swarm is the sum of all weights and thresholds in the BP neural network. The position of the $i$ particle is shown in the following equation.

$$
X_{i}=\left[x_{i 1}, x_{i 2}, \ldots, x_{i D}\right]^{\mathrm{T}}=\left[\begin{array}{ccc} 
& & \\
\omega_{11} & \ldots & \omega_{n l} \\
\omega_{1 m} & \ldots & \omega_{l m} \\
\theta_{1}^{1} & \ldots & \theta_{n}^{1} \\
\theta_{1}^{2} & \ldots & \theta_{n}^{2}
\end{array}\right]^{\mathrm{T}}
$$

where $\omega_{11}, \ldots, \omega_{n l}$ is the element of the weight matrix between the input layer nodes and the hidden layer nodes. $\omega_{1 \mathrm{~m}}, \ldots, \omega_{l m}$ is the element of the weight matrix between the hidden layer nodes and the output layer nodes. $\theta_{1}^{1}, \ldots, \theta_{n}^{1}$ is the element of the threshold matrix between the input layer nodes and the hidden layer nodes. $\theta_{1}^{2}, \ldots, \theta_{n}^{2}$ is the element of the threshold matrix between the hidden layer nodes and the output layer nodes. Initialize the position $x_{i d}^{0}$ and velocity $v_{i d}^{0}$ of the particles by equation and set a series of parameters such as the number of particles $N$, the maximum number of iterations $T_{\max }$, inertia weights $w$, learning factors $c_{1}$ and $c_{2}$ in the setting parameters stage.

Step 2: Calculate the fitness of the particle at this time, and record the position at this time to find the individual optimum and the global optimum of the current particle.

Step 3: Compare the fitness of the particle with the individual optimum and the global optimum. If the fitness of the particle is less than the individual optimum, then the current value is the individual optimum. If the current global optimum is greater than the individual optimum of the particle population, then the global optimum of the particle population is the individual optimum at this time.

Step 4: The optimal individual obtained by the PSO algorithm by updating the position and velocity is used as the initial weight and threshold of the BP neural network to train the BP neural network. When the network training reaches the maximum number of iterations or the mean square error is lower than the desired error, the training ends, and then the result is output, otherwise, it goes to Step 2 and continues to iterate until the algorithm converges.

Step 5: Perform network testing and compare the results for analysis.

\section{TRAINING TEST AND CASE APPLICATION OF IMPROVEMENT MODEL}

\subsection{Training test of the improvement model}

Only the data related to the earthquake are listed in the sample. The complete data set is shown in Tab. 5 below.

\begin{tabular}{|c|c|c|c|c|c|c|c|c|}
\hline No. & Time & Earthquake Level & $\begin{array}{l}\text { Damage } \\
\text { Intensity }\end{array}$ & Fence Intensity & $\begin{array}{l}\text { Housing } \\
\text { Collapse }\end{array}$ & $\begin{array}{c}\text { Affected } \\
\text { Population }\end{array}$ & Dead & Injured \\
\hline 1 & 1 & 6.0 & VI & 6 & 30655 & 243880 & 12 & 199 \\
\hline 2 & 1 & 6.9 & VIII & 7 & 3000 & 12000 & 0 & 3 \\
\hline 3 & 1 & 6.6 & VIII & 7 & 5469 & 10500 & 0 & 32 \\
\hline 4 & 1 & 7.0 & IX & 8 & 73671 & 176492 & 25 & 525 \\
\hline 5 & 1 & 6.7 & IX & 7 & 571 & 2546 & 1 & 0 \\
\hline 6 & 1 & 7.3 & IX & 7 & 13662 & 455573 & 0 & 0 \\
\hline 7 & 1 & 6.5 & IX & 7 & 900 & 1088400 & 617 & 3143 \\
\hline 8 & 1 & 7.0 & IX & 7 & 910 & 1520000 & 196 & 11470 \\
\hline 9 & 1 & 7.1 & IX & 7 & 3800 & 200000 & 2698 & 12135 \\
\hline 10 & 1 & 6.6 & VIII & 7 & 200000 & 870000 & 10 & 54 \\
\hline 11 & 1 & 6.1 & VIII & 7 & 7455 & 130311 & 5 & 132 \\
\hline 12 & 1 & 6.1 & VIII & 7 & 36500 & 103054 & 27 & 321 \\
\hline 13 & 2 & 6.4 & IX & 9 & 360000 & 186000 & 3 & 562 \\
\hline 14 & 1 & 6.5 & VII & 7 & 31932 & 995000 & 7 & 199 \\
\hline 15 & 1 & 7.0 & VIII & 7 & 959000 & 1075000 & 309 & 16912 \\
\hline 16 & 1 & 6.6 & IX & 7 & 86 & 120000 & 1 & 151 \\
\hline 17 & 1 & 7.6 & IX & 7 & 1858800 & 2500000 & 743 & 4105 \\
\hline 18 & 1 & 6.8 & IX & 7 & 40500 & 536000 & 3 & 313 \\
\hline 19 & 1 & 7.9 & $\mathrm{X}$ & 7 & 18567 & 1500000 & 2175 & 2756 \\
\hline 20 & 2 & 7.9 & XI & 5 & 656136 & 2300000 & 242000 & 164000 \\
\hline
\end{tabular}

Table 5 The Complete Data Set

First, the output data were normalized, and then the data after the principal component analysis were normalized together with the output data to be in the range of $(0,1)$, which is beneficial for the subsequent training of the network. The normalized data are shown in Tab. 6 below. 
Table 6 The Normalized Data

\begin{tabular}{|c|c|c|c|c|c|c|c|c|}
\hline \multirow{2}{*}{$\begin{array}{c}\text { No. } \\
1\end{array}$} & \multicolumn{6}{|c|}{ Input vectors } & \multicolumn{2}{|c|}{ Output vectors } \\
\hline & 0 & 0.4276 & 0.0426 & 0.1689 & 0.9676 & 1 & 0.8322 & 0.8025 \\
\hline 2 & 0 & 0.2670 & 0.6035 & 1 & 0.4516 & 0.5199 & 0.5715 & 0.5219 \\
\hline 3 & 0 & 0.4248 & 0.8221 & 1 & 0.7340 & 0.7593 & 0.7776 & 0.7267 \\
\hline 4 & 0.2518 & 0.0140 & 1 & 0.7912 & 0 & 0.0914 & 0.2495 & 0.2180 \\
\hline 5 & 0 & 0.0451 & 0.6960 & 1 & 0.4556 & 0.2650 & 0.3974 & 0.3493 \\
\hline 6 & 0.2739 & 0 & 0.2913 & 1 & 0.0216 & 0.2389 & 0.1478 & 0.1061 \\
\hline 7 & 0.1589 & 0 & 0.2523 & 0.6910 & 0.2278 & 1 & 0.2071 & 0.2132 \\
\hline 8 & 0.6040 & 0.7031 & 0.0095 & 0.7540 & 0.5805 & 1 & 0 & 0.2149 \\
\hline 9 & 0.1578 & 0 & 0.4408 & 1 & 0.1736 & 0.1914 & 0.2619 & 0.3975 \\
\hline 10 & 0.0227 & 0.3181 & 0.0729 & 0.4152 & 0 & 1 & 0.3733 & 0.3031 \\
\hline 11 & 0 & 0.7264 & 0.4835 & 0.2079 & 1 & 0.3564 & 0.3861 & 0.3648 \\
\hline 12 & 0 & 0.7408 & 0.4886 & 0.2028 & 1 & 0.3410 & 0.3899 & 0.3700 \\
\hline 13 & 0.2407 & 0.3747 & 1 & 0 & 0.1969 & 0.3601 & 0.2473 & 0.2375 \\
\hline 14 & 0 & 0.4035 & 0.1269 & 0.2724 & 0.2787 & 1 & 0.4514 & 0.4199 \\
\hline 15 & 0.5510 & 1 & 0.0184 & 0.0619 & 0 & 0.1501 & 0.2339 & 0.4178 \\
\hline 16 & 0 & 0.0639 & 0.7285 & 1 & 0.5146 & 0.3897 & 0.4330 & 0.3844 \\
\hline 17 & 0.8564 & 1 & 0.0207 & 0.1014 & 0 & 0.1582 & 0.1798 & 0.1865 \\
\hline 18 & 0.0385 & 0.6452 & 0.4725 & 0.8763 & 1 & 0.2280 & 0.0689 & 0 \\
\hline 19 & 0.9344 & 0.8461 & 0.2258 & 1 & 0.6687 & 0.3353 & 0.0162 & 0 \\
\hline 20 & 1 & 0 & 0.2852 & 0.1985 & 0.3667 & 0.2888 & 0.7750 & 0.7708 \\
\hline
\end{tabular}

The sample set and test set were selected by random sampling, and a total of 20 sets of data were collected. $80 \%$ of the total sample was set as the training sample, $10 \%$ of the total sample was set as the test sample, and $10 \%$ of the total sample was set as the change sample. The results after random assignment are represented in Tab. 7 below.

Table 7 Sample Sets

\begin{tabular}{|c|c|}
\hline Sample set & Sample No. \\
\hline Training Sample & $1-10,11,13,15,17-19$ \\
\hline Test Sample & 12,16 \\
\hline Change Sample & 14,20 \\
\hline
\end{tabular}

In this paper, we first let the number of nodes in the hidden layer vary in the range of 8 to 14 according to the actual problem under study, and then train the network on them one by one to arrive at the optimal number of nodes in the hidden layer by comparative analysis. When the number of nodes in the hidden layer is 9 , the total error of the network output is 0.0016099 , which is the minimum value of the network output error when the number of nodes in the hidden layer varies in the range of 8 - 14. Fig. 2 shows the structure of the BP neural network constructed in this paper.

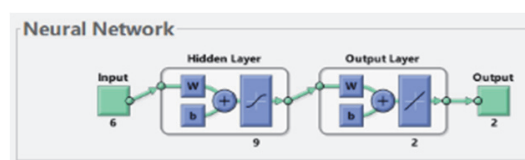

Figure 2 Structure Diagram of BP Neural Network Run by Matlab

In this paper, the initial weights and thresholds of the BP neural network are optimized with the PSO algorithm. Firstly, the parameters are encoded, the input vector of the network is 6 - dimensional, the number of nodes in the hidden layer is 9 , and the output vector is 2 - dimensional, so the sum of the weights and thresholds is 83 , and the population size is 40 . The initial weights and thresholds of the BP neural network are the optimal solutions obtained by the PSO algorithm optimization, and the results are shown in Tab. 8, Tab. 9, Tab. 10, and Tab. 11.

Table 8 Initial Weight $w_{1}$

\begin{tabular}{|c|c|c|c|c|c|}
\multicolumn{7}{|c|}{ Table 8 Initial Weight $w_{1}$} \\
\hline \multicolumn{7}{|c|}{ Initial weight $w_{1}$} \\
\hline 0.257888 & 0.183716 & 0.877365 & -0.57852 & 0.330497 & 0.001148 \\
\hline 0.094189 & 0.798451 & -0.82516 & 0.220992 & -0.18971 & 0.631392 \\
\hline 0.523281 & 0.796078 & -0.34519 & -0.41693 & -0.37422 & 0.673652 \\
\hline 0.425258 & 0.683398 & 0.463342 & -0.03473 & 0.784032 & 0.096092 \\
\hline-0.10495 & 0.522025 & 0.736198 & -0.02795 & -0.32538 & -0.5866 \\
\hline 0.51085 & -0.14663 & -0.02651 & 0.629306 & -0.95807 & -0.5866 \\
\hline-0.26759 & -0.29053 & 0.626981 & -0.25567 & -0.58383 & 0.227898 \\
\hline-0.87102 & 0.025229 & 0.298288 & 0.29166 & -0.16073 & 0.580578 \\
\hline-0.62066 & -0.3714 & -0.73207 & 0.477368 & 0.004277 & 0.173689 \\
\hline
\end{tabular}

Table 9 Initial Weight $w_{2}$

\begin{tabular}{|c|c|c|c|c|c|c|c|c|}
\hline \multicolumn{7}{|c|}{ Initial weight $w_{2}$} \\
\hline-0.27652 & -0.56328 & 0.11662 & 0.12556 & 0.53348 & 0.61790 & -0.76023 & -0.53243 & 0.518144 \\
\hline-0.35112 & -0.47068 & 0.56564 & 0.66121 & -0.48597 & 0.41216 & -0.46922 & 0.38195 & 0.63768 \\
\hline \multicolumn{7}{|c|}{ Initial Threshold $B_{1}$} \\
\hline 0.665 & -0.9184 & -0.5223 & 0.0748 & 0.3685 & 0.464 & 0.019 & 0.01679 & -0.795 \\
\hline
\end{tabular}

Table 11 Initial Threshold $B_{2}$ Initial Threshold $B_{2}$

\begin{tabular}{|l|r|}
\hline \multicolumn{3}{|c|}{ Initial Threshold $B_{2}$} \\
\hline 0.3604 & 0.92889 \\
\hline
\end{tabular}

The initial weights and thresholds of the proposed prediction model are shown in Tab. 12, Tab. 13, Tab. 14 and Tab. 15, and then the sample data to be predicted are substituted into the model to obtain the prediction results 
of injury rate and mortality rate.

In the network testing phase, the model is tested using the change samples and test samples in Chapter 4. The initial weights and thresholds obtained above were substituted into the model, and the prediction results were obtained as shown in Tab. 12.

\begin{tabular}{|c|c|c|c|c|c|c|c|c|c|}
\hline \multirow[b]{2}{*}{ Method } & \multirow[b]{2}{*}{ Sample set } & \multicolumn{4}{|c|}{ Dead } & \multicolumn{4}{|c|}{ Injured } \\
\hline & & $\begin{array}{l}\text { Output } \\
\text { value }\end{array}$ & $\begin{array}{l}\text { Actual } \\
\text { value }\end{array}$ & Absolute error & $\begin{array}{c}\text { Network Total } \\
\text { Error }\end{array}$ & $\begin{array}{l}\text { Output } \\
\text { value }\end{array}$ & $\begin{array}{c}\text { Actual } \\
\text { value }\end{array}$ & Absolute error & $\begin{array}{c}\text { Network Total } \\
\text { Error }\end{array}$ \\
\hline \multirow{4}{*}{ PSO-BP } & 12 & -0.0456 & 0.2235 & 0.2691 & \multirow{4}{*}{0.9439} & -0.0134 & -0.0379 & 0.0245 & \multirow{4}{*}{0.5475} \\
\hline & 16 & -0.5569 & -0.4026 & 0.1543 & & -0.3599 & -0.4539 & 0.0940 & \\
\hline & 14 & -0.4238 & -0.2688 & 0.1550 & & -0.5389 & -0.3247 & 0.2142 & \\
\hline & 20 & -0.0454 & -0.4109 & 0.3655 & & -0.2179 & -0.4327 & 0.2148 & \\
\hline \multirow{4}{*}{ BP } & 3 & 0.6237 & -0.1546 & 0.7783 & \multirow{4}{*}{2.2289} & -0.0205 & 0.1448 & 0.1653 & \multirow{4}{*}{1.2487} \\
\hline & 5 & -0.4490 & -0.4034 & 0.0456 & & 0.1626 & -0.4537 & 0.6163 & \\
\hline & 13 & -0.7589 & -0.3828 & 0.3761 & & -0.6938 & -0.4236 & 0.2702 & \\
\hline & 19 & -1.4458 & -0.4169 & 1.0289 & & -0.5549 & -0.3580 & 0.1969 & \\
\hline
\end{tabular}

The change samples and test samples of the two models are different because of the random assignment method used in the sample allocation. From the above table, it can be seen that the total errors of the models constructed in this paper in predicting mortality rate and injury rates are 0.9439 and 0.5475 , both of which are smaller than the total errors predicted by the BP neural network alone. Moreover, the absolute errors of the PSO algorithm combined with the BP neural network are in the range of $0.02-0.37$, while the absolute errors of the BP neural network alone are in the range of $0.04-1.1$. Therefore, in general, the prediction results of the PSO algorithm optimized for the BP neural network are better than those of the BP neural network.

Next, the mean square error between the simulated and expected outputs of the change and test samples is calculated. The error values of mortality rate are represented by msTestError1 and msValidateError1, and the error values of injury rate are represented by msTestError2 and msValidateError2. The calculation results are shown in Tab. 13.

\begin{tabular}{|c|c|c|c|}
\multicolumn{4}{|c}{ Table 13 Comparison of MSE } \\
\hline \multirow{2}{*}{ Method } & Sample set & $\begin{array}{c}\text { Mean square error } \\
\text { of mortality rate }\end{array}$ & $\begin{array}{c}\text { Injury rate mean } \\
\text { square error }\end{array}$ \\
\hline \multirow{2}{*}{ PSO-BP } & $\begin{array}{c}\text { Change } \\
\text { Sample }\end{array}$ & 0.0357634 & 0.0687964 \\
\cline { 2 - 4 } & Test Sample & 0.0534786 & 0.0498745 \\
\hline \multirow{2}{*}{ BP } & $\begin{array}{c}\text { Change } \\
\text { Sample }\end{array}$ & 0.1398657 & 0.2458798 \\
\cline { 2 - 4 } & Test Sample & 0.0984653 & 0.5368954 \\
\hline
\end{tabular}

From the above table, it can be seen that the mean square error of the prediction results after the combination of PSO algorithm and BP neural network is smaller than that of BP neural network alone for both injury rate and mortality rate, and both are less than 0.07 , which proves the effectiveness of the network.

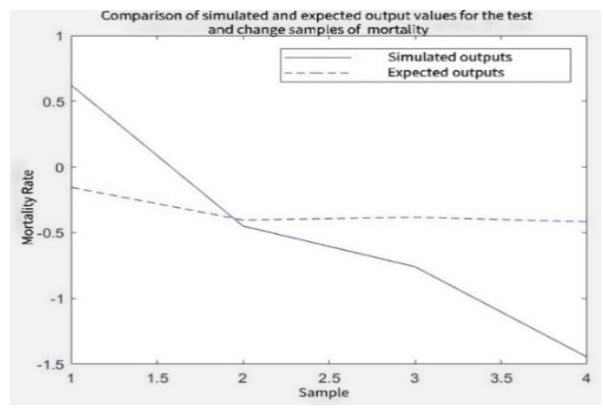

Figure 3 Comparison of Mortality Rate
The expected and simulated outputs of the combined PSO-BP model and the BP neural network for the change and test samples are compared graphically. Fig. 3 and Fig. 4 show the simulated and expected outputs of the BP neural network for predicting mortality rate and injury rate.

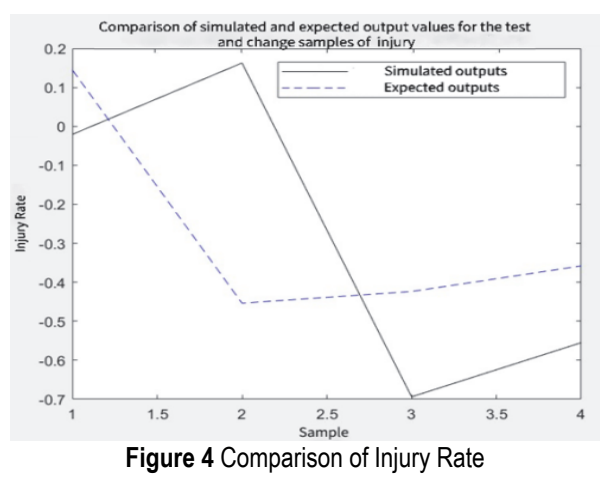

The comparison of the simulated and desired output values for the prediction of mortality and injury rates after the combination of PSO algorithm and BP neural network is shown in Fig. 5 and Fig. 6.

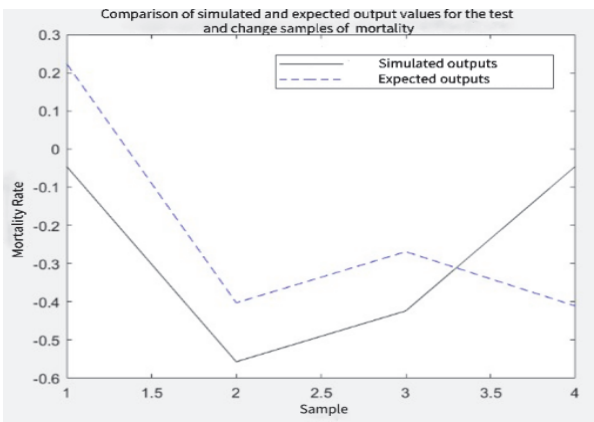

Figure 5 Comparison of Mortality Rate

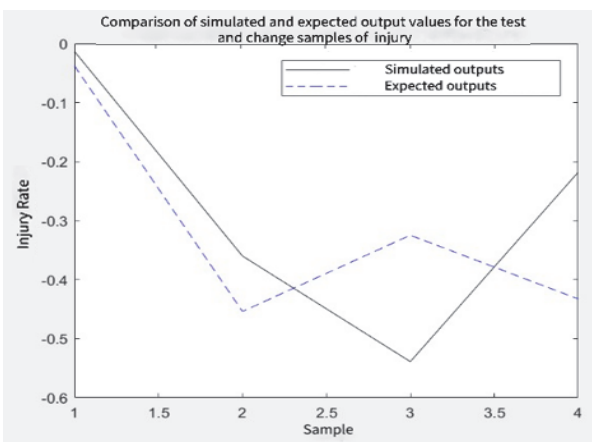

Figure 6 Comparison of Injury Rate 
Comparing the above images, it can be seen that the prediction of mortality rate and injury rate of people in earthquakes after the improvement of BP neural network with PSO algorithm, the fit between the predicted and actual values is significantly better than the prediction with BP neural network alone, thus also proving the effectiveness and accuracy of this model.

\subsection{Case Application}

In this paper, we collected data on the predicted indicators of the 2017 Jiuzhaigou earthquake, as shown in Tab. 14. The Jiuzhaigou earthquake occurred at 21:19:46 on August 8, 2017, so the time is recorded as 1; the magnitude is 7 , the damage intensity is 9 , the local buildings are set at intensity 8 , a total of 73,671 houses have different degrees of collapse, the affected population is 176,492 , and the local population density is about 6 people $/ \mathrm{km}^{2}$, and the earthquake was not able to forecast well before it occurred, so the prediction level is 1 .

Table 14 Forecasting Index Data of Jiuzhaigou Earthquake

\begin{tabular}{|c|c|c|c|c|c|c|c|}
\hline Time & $\begin{array}{c}\text { Earthquake } \\
\text { Level }\end{array}$ & $\begin{array}{c}\text { Damage } \\
\text { Intensity }\end{array}$ & Fence Intensity & $\begin{array}{c}\text { Housing } \\
\text { Collapse }\end{array}$ & $\begin{array}{c}\text { Affected } \\
\text { Population }\end{array}$ & $\begin{array}{c}\text { Population } \\
\text { Density }\end{array}$ & $\begin{array}{c}\text { Forecast } \\
\text { Level }\end{array}$ \\
\hline 1 & 7.0 & IX & 8 & 73671 & 176492 & 6 & 1 \\
\hline
\end{tabular}

The data as above are first standardized. The processing should be combined with the sample set data in Chapter 4 and then unified for standardization, after which the data for this case is extracted. The data after processing are shown in Tab. 15. Substituting the data in Tab. 15 into Eq. (5), its first six principal component data can be obtained, as shown in Tab. 16. The data in Tab. 16 are merged into the vectors in Tab. 4 for uniform normalization, and the processed data are shown in Tab. 17. The data in Tab. 17 are used as the input vectors of the prediction model, and the constructed BP neural network is run to obtain the following results. The data in Tab. 18 are inverted and normalized, and the results are shown in Tab. 19.

\begin{tabular}{|c|c|c|c|c|c|c|c|}
\hline Time & Earthquake Level & $\begin{array}{l}\text { Damage } \\
\text { Intensity }\end{array}$ & Fence Intensity & $\begin{array}{l}\text { Housing } \\
\text { Collapse }\end{array}$ & $\begin{array}{c}\text { Affected } \\
\text { Population }\end{array}$ & $\begin{array}{c}\text { Population } \\
\text { Density }\end{array}$ & $\begin{array}{c}\text { Forecast } \\
\text { Level }\end{array}$ \\
\hline-0.3166 & 0.3052 & 0.3722 & 1.2870 & -0.2992 & -0.6644 & -0.3028 & -0.7049 \\
\hline
\end{tabular}

Table 16 Scores of the Top 6 Principal Components

\begin{tabular}{|c|c|c|c|c|c|}
\hline Time & Earthquake Level & Damage Intensity & Fence Intensity & Housing Collapse & Affected Population \\
\hline-0.6913 & -0.1394 & 0.9741 & 0.9383 & -0.8117 & -0.1874 \\
\hline
\end{tabular}

Table 17 Normalized data

\begin{tabular}{|c|c|c|c|c|c|}
\hline Time & Earthquake Level & Damage Intensity & Fence Intensity & Housing Collapse & Affected Population \\
\hline 0.1570 & 0.4109 & 0.5026 & 0.7509 & 0.0866 & 0.2230 \\
\hline
\end{tabular}

\begin{tabular}{|c|c|c|}
\hline Table 18 Output Value of Network \\
\hline Sample & Injury Rate & Mortality rate \\
\hline Jiuzhaigou & 0.3675 & 0.5856 \\
\hline
\end{tabular}

Table 19 Output Value of Network After Denormalization

\begin{tabular}{|c|c|c|}
\hline Sample & Injury Rate & Mortality rate \\
\hline Jiuzhaigou & -0.2597 & -0.7866 \\
\hline
\end{tabular}

Inverse normalization of the data in the above table gives the number of casualties, which results in 19 injured and 473 dead. After checking, it is known that the total population of Jiuzhaigou is about 300,000 , according to which the number of survivors in the earthquake can also be obtained. The specific data are shown in Tab. 20. The specific supplies estimated in this paper are compressed cookies and drinking water in the food category, tents and sleeping bags in the cold items category, and antiinflammatory drugs in the medical category. The correlation coefficients are set as shown in Tab. 21 .

Table 20 Casualty Data of Jiuzhaigou Earthquake
\begin{tabular}{|c|c|c|c|}
\hline Sample & Injured & Dead & Survivors \\
\hline Jiuzhaigou & 19 & 473 & 299527 \\
\hline
\end{tabular}

Table 21 Correlation Coefficient Setting

\begin{tabular}{|c|c|c|c|c|c|c|c|}
\hline $\begin{array}{c}a^{k_{11}} / \\
\mathrm{ml} /\end{array}$ & \begin{tabular}{c}
$a^{k_{12}} / \mathrm{g} / \mathrm{h}$ \\
\hline 160
\end{tabular} $5^{a^{k_{21}}} /$ one/h & $\begin{array}{c}a^{k_{22}} \\
/ \text { one/h }\end{array}$ & $\begin{array}{c}a^{k_{31}} \\
/ \mathrm{mg} / \mathrm{h}\end{array}$ & $\partial$ & $Z_{\partial}$ & $L T$ \\
\hline & 0.25 & 1 & 80 & 0.02 & 2.05 & 5 \\
\hline
\end{tabular}

In the above table, $a^{k_{11}}$ represents drinking water, $a^{k_{12}}$ represents compressed cookies, $a^{k_{21}}$ represents tent, $a^{k_{22}}$ represents sleeping bag, and $a^{k_{31}}$ represents antiinflammatory medicine. The values set in this paper are estimates [16], because there are many types of antiinflammatory drugs and their demand will vary according to the degree of injury. In this paper, the supply satisfaction rate is set to $98 \%$, the corresponding service factor is 2.05 , and the lead time is set to 5 hours.

$\sigma^{k}(0)=0$ is the initial moment. The demand for these kinds of supplies is estimated, as shown in Tab. 22.

\begin{tabular}{|c|c|c|c|c|}
\multicolumn{7}{|c|}{ Table 22 Demand for Supplies } \\
\hline $\begin{array}{c}\text { drinking } \\
\text { water / } \mathrm{ml}\end{array}$ & $\begin{array}{c}\text { compressed } \\
\text { cookies / g }\end{array}$ & $\begin{array}{c}\text { Tent / } \\
\text { one }\end{array}$ & $\begin{array}{c}\text { sleeping } \\
\text { bag / one }\end{array}$ & $\begin{array}{c}\text { anti- } \\
\text { inflammatory } \\
\text { medicine / mg }\end{array}$ \\
\hline 239621600 & 74881750 & 74890 & 299530 & 7600 \\
\hline
\end{tabular}

By estimation, the quantity of drinking water, compressed cookies, tents, sleeping bags, and antiinflammatory drugs that the government emergency section needs to deliver to the disaster area immediately after the Jiuzhaigou earthquake is shown in Tab. 22.

Gradually, as time passes, the casualties and demand information of the disaster area will be shared accurately. Therefore, in the ensuing time, the emergency department 
will have to continuously adjust the amount of emergency supplies delivered to the affected areas and continue to forecast information about the needs of the affected areas.

\section{CONCLUSION}

Earthquakes have occurred from time to time, and large earthquake not only causes huge property damage, but also endangers people's lives seriously. In order to mitigate the consequences caused by earthquakes, it is important to meet the needs of people in the affected areas for emergency supplies timely while carrying out immediate rescue operations. Therefore, it is essential to estimate the demand for emergency supplies quickly. However, due to the instantaneous nature of earthquakes, it is difficult for the government to know the needs in the quake zone at the first instance, and it will not be able to get the demand accurately for supplies in the affected areas. That is the reason why it is necessary to predict the demand for emergency supplies after a large earthquake, which is more conducive to the dispatch of supplies. The main research results of this paper are as follows:

(1) For predicting the demand for large earthquake emergency supplies, this paper adopts an indirect prediction method. First, the BP neural network is improved with the PSO algorithm to optimize the initial weights and thresholds of the BP neural network to avoid falling into local optimum. And the improved model is used to predict the injury rate and mortality rate of large earthquake. By comparing the improved BP neural network before and after the improvement, it was found that the improved model has higher prediction accuracy, smaller prediction error, and better fitting of the simulated value to the desired output value.

(2) After predicting the injury rate and mortality rate of large earthquake, the number of injured and survivors are calculated based on the total population of the disaster area And then the quantity relationship between the number of injured and survivors and different emergency supplies is used to estimate the demand for supplies. The supplies include drinking water and compressed cookies in the food category, tents and sleeping bags in the cold goods category, and anti-inflammatory drugs in the medical goods category.

In this paper, the following deficiencies exist in the prediction of the demand for large earthquake emergency supplies.

(1) When selecting variables, based on the availability of data this paper selected eight variables, but the factors affecting the earthquake casualty rate are actually complex. Meanwhile, more variables can be considered in the subsequent study to make the prediction more accurate.

(2) This paper only estimates the emergency supplies needed in the first time after a large earthquake, without considering the dynamic change of time. In the subsequent study, we can calculate the demand of supplies according to the dynamic change of time.

(3) Because of the similarity of considerations, the later study can be extended to other country regions.

\section{Acknowledgments}

This work is supported by Beijing Logistics
Informatics Research Base.

\section{REFERENCES}

[1] Xue, R. (2014). Research on the demand and distribution of emergency materials. Master's thesis, Xi'an University of Science and Technology.

https://kns.cnki.net/KCMS/detail/detail.aspx?dbname=CMF D201501\& filename $=1014072622 . n h$.

[2] Li, L. (2013). Research on prediction of demand for largescale earthquake emergency relief materials based on grey modeling technique. Master's thesis, Chongqing University of Technology and Industry.

https://kns.cnki.net/KCMS/detail/detail.aspx?dbname=CMF D201401\& filename $=1014119245 . \mathrm{nh}$

[3] Nie, G., Gao, J., Su, G., Wang, J. (2001). Modeling of earthquake emergency relief needs-An empirical analysis from earthquake episodes. Resource Science, (01), 69-76.

[4] Chen, X. \& Liu, Z. (2015). Demand Forecast of Emergency Supplies Based on Gray Model.(eds.) Proceedings of 2015 International Conference on Advances in Mechanical Engineering and Industrial Informatics (AMEII 2015), 13831387. https://doi.org/10.2991/ameii-15.2015.250

[5] Guo, J. F. \& Zhou, G. (2011). Research on the demand forecasting method for large-scale earthquake emergency supplies. Value Engineering, (22), 27-29.

[6] He, S. \& Zhu, W. (2015). An improved support vector machine based demand forecasting model for earthquake emergency supplies. Logistics Science and Technology, (11), 39-42. doi:10.13714/j.cnki.1002-3100.2015.11.012.

[7] Sun, C. (2016). Research on the classification and demand of emergency supplies for large earthquake disasters. Master's thesis, Nanjing University of Technology. https://kns.cnki.net/KCMS/detail/detail.aspx?

[8] Cheng, Q. Q. (2016). GA-based BP neural network for earthquake emergency material demand prediction. Master's thesis, Southwest University of Finance and Economics). https://kns.cnki.net/KCMS/detail/detail.aspx?dbname=CMF D201701\&filename $=1017017079 . \mathrm{nh}$

[9] Zhou, M. (2019). Simulation study on demand prediction and supply strategy of emergency materials under earthquake disaster. Master's thesis, Beijing Jiaotong University.

https://kns.cnki.net/KCMS/detail/detail.aspx?dbname=CMF D202001\& filename $=1019190352 . \mathrm{nh}$

[10] Aminian, F., Suarez, E. D., Aminian, M., \& Walz, D. T. (2006). Forecasting economic data with neural networks. Computational Economics, 28(1), 71-88. https://doi.org/10.1007/s10614-006-9041-7

[11] Mamat, T., Jumaway, M., Zhang, X., \& Hassan, M. (2018). Research on impact factors of agricultural mechanization development level based on BP neural network. J. Agric. Mech. Res, 40, 21-25.

[12] Chi, S. \& Wang, L. (2021). Calculation Method of Probability Integration Method Parameters Based on MIVGP-BP Model. Tehnički vjesnik, 28(1), 160-168. https://doi.org/10.17559/TV-20200429151307

[13] Lazar, M., Javoršek, D., \& Hladnik, A. (2020). Study of Camera Spectral Reflectance Reconstruction Performance using CPU and GPU Artificial Neural Network Modelling. Tehnički vjesnik, 27(4), 1204-1212. https://doi.org/10.17559/TV-20190526202030

[14] Qiao, H. (2009). Research on the classification and demand of emergency material requirements. Master's thesis, Beijing Jiaotong University. https://kns.cnki.net/KCMS/detail/detail.aspx?dbname=CMF D2009\& filename $=2009146797 . \mathrm{nh}$

[15] Zhou, L., Chen, X., Chen, H., \& Peng, M. (2008). A study on the characteristics of disaster relief supplies in emergency 
situations-An example of food supply in Wenchuan earthquake. Management Review, (12), 25-29+63. https://doi.org/10.1088/1126-6708/2008/06/008

[16] Zhang, Y. (2008). Research on the theory and method of disaster relief material logistics decision based on natural disasters. Doctoral dissertation, Chang'an University. https://kns.cnki.net/KCMS/detail/detail.aspx?dbname $=\mathrm{CDF}$ D0911\&filename $=2009176684 . \mathrm{nh}$

\section{Contact information:}

\section{Dan CHANG}

School of Economics and Management,

Beijing Jiaotong University,

No.3 Shangyuancun, Haidian District, Beijing, China

E-mail: dchang@bjtu.edu.cn

\section{Yan WANG}

(Corresponding author)

School of Economics and Management,

Beijing Jiaotong University,

No.3 Shangyuancun, Haidian District, Beijing, China

E-mail:19120566@bjtu.edu.cn

\section{Rui FAN}

Information Technology Institute of China Railway Taiyuan Bureau Group Co No. 185, North Construction Road,

Xing Hua Ling District, Taiyuan, Shanxi, China

E-mail:810966067@qq.com 